\title{
Non-random mating in natural populations of the seaweed fly, Coelopa frigida
}

T. H. Day and

R. K. Butlin*
Department of Genetics, University of Nottingham, University Park, Nottingham NG7 2RD.

Experiments are reported that were designed to test for the randomness of mating in seaweed flies (Coelopa frigida) with respect to size, to genotypes at the alcohol dehydrogenase $(A d h)$ locus, and to a chromosomal inversion with which the $A d h$ locus is associated. Mating was allowed to occur in samples of wild animals, and the females then individually invited to lay eggs. By determining the genotypes of the mother and her progeny, the father's genotype could be inferred. The observed distribution of matings was then compared with expectations assuming random mating. It was found that animals mated in a positively assortative fashion with respect to their size, but disassortatively with respect to the $A d h$ locus and the $\alpha / \beta$ inversion on chromosome I. Large females tended to mate with large males, but not with males of their own $A d h$ genotype. Mechanisms that might give rise to this pattern of non-randomness are discussed. The consequences of disassortment are that it would be expected to contribute to the maintenance of genetic variation.

\section{INTRODUCTION}

It is assumed by many population biologists that animals mate randomly. Since 1908 the HardyWeinberg law, which, of course assumes panmixia, has been used by population geneticists, and it has, apparently, served them well. However in the last 10 years it has become evident that many animals do not mate at random (see review by Partridge, 1983). Very frequently animals mate with their own, rather than with some different type. Such positively assortative mating has been observed in arthropods (Halliburton and Gall, 1981; Johnson, 1982; McLain, 1982; Christy, 1983), fish (Warner and Harlan, 1982), many species of amphibians (see review by Arak, 1983), and birds (Cooke and Davies, 1983). In all these examples, the assortment is with respect to sizelarge animals mate with large, and small with small. Often the assortment is with respect to colour (Cooch and Beardmore, 1959; Grant et al., 1974; Barlow and Rogers, 1978; O'Donald, 1980; Majerus et al., 1982a; Cooke and Davies, 1983), but may involve a variety of characters such as allozymes (Sassaman, 1978), time of breeding

\footnotetext{
* Present address: School of Biological Sciences, University of
} East Anglia, Norwich NR4 7TJ.
(O'Donald, 1972), chromosomal inversions (Stalker, 1976) or degree of inbreeding (Wong et al., 1982). The idea of non-random mating must be a familiar one, since there is strong positive assortment in our own species with respect to many characters (e.g., physical characteristics-Kiser, 1968; and educational attainment-Spuhler, 1968).

What is perhaps surprising is that there are so few examples of negative assortment-like mating with unlike (see discussion by Burley, 1983). The most convincing examples include the work on the scarlet tiger moth (Sheppard, 1952), white throated sparrows (Lowther, 1961), and feral pigeons (Murton et al., 1973; Murton and Westwood, 1977). In all three species there is a clearly defined visual polymorphism with a simple genetic basis. Negative assortment may also occur between different laboratory strains of mice (Yanai and McClearn, 1972, 1973a, 1973b) and of Drosophila melanogaster (Averhoff and Richardson, 1974, 1976-but see van den Berg et al., 1984), and Yamazaki et al., (1976, 1978) and Lenington (1983) have presented evidence that mice may mate disassortatively with respect to the $H-2$ and $t$ loci. Finally, Bateson (1983) has demonstrated that Japanese quail may mate with animals exhibiting some intermediate level of dissimilarity to 
themselves. This suggests that there may not be a clear cut distinction between positive and negative assortment. Both may occur simultaneously for different characters, or there may be discrimination in favour of an optimal degree of difference.

We think this catalogue of examples is now sufficiently impressive that it is no longer justified to assume, in any particular species, that mating is random unless there is supporting evidence.

In the seaweed fly, Coelopa frigida, there are large variations in the reproductive success of males (Butlin et al., 1982a; Day et al., 1987), and also significant differences in the fecundities of individuals (Butlin et al., 1985). This report is concerned with a further aspect of reproductionwho mates with whom?

In seaweed flies there is considerable variation in the size of animals, particularly of males, and this is known to be partly genetically determined (Butlin et al., 1982a). Flies homokaryotypic for the $\alpha$ chromosome $I$ inversion are substantially larger than $\beta \beta$ individuals. $\alpha \beta$ flies are intermediate in size. In view of the common finding that animals mate non-randomly with respect to size, we have tested for assortment with respect to size, and with respect to the alcohol dehydrogenase locus $(A d h)$ which is known to be associated with the $\alpha \beta$ inversion system (Day et al., 1982). The results indicate that flies mate assortatively with respect to their size, but disassortatively with respect to the $A d h$ locus and the $\alpha \beta$ inversion. Possible causes and consequences of this nonrandom mating are discussed.

\section{MATERIALS AND METHODS}

The materials and experimental procedures are fully described in the accompanying paper (Day et al., 1987).

\section{RESULTS}

The technique of studying the progeny of isolated individual females is an exceedingly laborious one. In consequence, only one of the nine samples yielded data on more than 100 matings. Since there are usually 5 common $A d h$ genotypes in natural populations, there are 25 different types of matings. This inevitably means that in a $5 \times 5$ table of matings, most of the boxes contain very low numbers, and a standard $\chi^{2}$ analysis would be unreliable and misleading.
Instead we have used a rather less familiar technique of analysis that can cope with low numbers. The data comprise a contingency table with three dimensions of classification: 5 male genotypes $\times 5$ female genotypes $\times 9$ independent samples (see Appendix). If there is non-random mating this will generate an interaction between male genotypes and female genotypes that is consistent over all samples, despite variation in genotype frequencies between samples.

Two questions are being asked: is there a significant male-female interaction, and secondly, is this consistent between samples? In simple terms what we have done is to programme a computer to mate at random a given number of males and females, the only constraint being that the total number of males and females of each genotype should be the same as were actually analysed in practice. This was repeated more than 100 times for each of the nine samples to generate a large number of $5 \times 5$ tables. This procedure provides an estimate of the random variation in interaction between male and female genotypes, as well as the residual variation due to differences in this interaction between experiments. The male-female interaction and residual variation were also calculated from the actual data, and then compared with the distribution of simulated data. If the actual values lie outside these simulated distributions, we conclude that mating has not been random.

More specifically, we have fitted the observed values to a log-linear model assuming a Poisson error distribution using the Genstat statistical package (copyright owned by Lawes Agricultural Trust, Rothamstead Experimental Station, Harpenden, Herts, U.K.). This method yields the "deviance" as defined by Nelder and Wedderburn (1972). The significance of these estimates has been assessed by generating randomly fitted contingency tables using the Royal Statistical Society algorithm No. AS 159, and then fitting them to the log-linear model.

The distribution of the results from the random tables, and the actual experimental data are given in fig. 1. It is clear that the observed male-female genotype interactions is much greater than is expected by chance $(p<0.01)$, whereas the residual variation is within the expected range. We therefore conclude that there is evidence for nonrandom mating with respect to the $A d h$ locus, and that this non-randomness is consistent between samples.

This analysis does not provide any information on the nature of the non-randomness. However, since there is no evidence for heterogeneity 

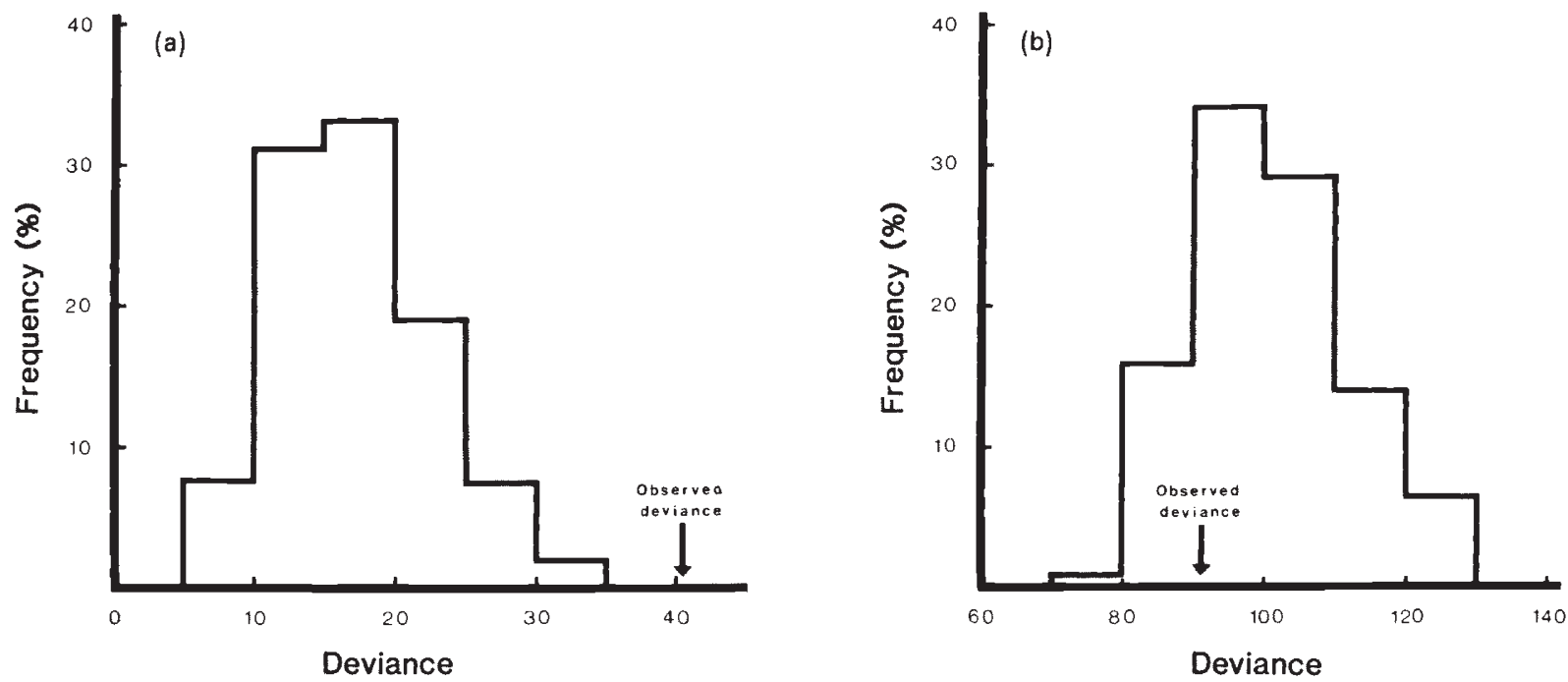

Figure 1. (a) Expected distribution of deviance due to male $\times$ female interaction. The distribution is derived from computer simulations assuming random mating (see text for details). The interaction deviance of the observed results lies outside the expected distribution. (b) Expected distribution of residual deviance. The residual deviance of the observed results lies within the expected distribution.

between samples (at least in this respect), the data can now be pooled to yield sufficiently large numbers for a conventional contingency analysis. Firstly, and as expected, there is a very highly significant overall departure from randomness $\left(\chi^{2}=35 \cdot 6, p \ll 0 \cdot 001\right)$. In order to identify which matings are deviating most from expectations we have calculated the adjusted residual for each mating (see Haberman, 1973). Of the 16 matings for which there is a valid test, 5 matings are in significant excess of expectations, and 5 in significant deficiency (see Appendix). We shall discuss the pattern of these deviations in a later section.

\section{Is there non-random mating with respect to} the $\alpha / \beta$ inversion polymorphism?

Although we have used alleles at the $A d h$ locus to identify matings, it seems most improbable that this locus is the one determining the non-randomness. The $\alpha \beta$ inversion with which the $A d h$ locus is tightly linked (Day et al., 1982), is a very large one including approximately one tenth of the total genome. It seems probable that one or more other loci are directly involved. Accordingly we have examined the pattern of mating with respect to the inversion karyotypes.

The $A d h-B$ allele is tightly associated with the $\alpha$-chromosomal sequence and the $A d h-D$ allele with the $\beta$-sequence. However, the $A d h-C$ allele is found with both sequences. Two approaches are possible. The $A d h$ genotypes can be lumped so that $A d h-B B$ and $B C$ are classified as "mostly $\alpha \alpha$ ", $C D$ and $D D$ as "mostly $\beta \beta$ " and $B D$ animals as $\alpha \beta$ (table 1). This results in a $3 \times 3$ table with no loss of data but with ambiguity introduced because of the $A d h-C$ allele. In this case there is a highly significant departure from random mating $\left(\chi^{2}=31 \cdot 1, p \ll 0.001\right)$. Alternatively, if those animals bearing $C$ alleles are completely omitted from the analysis, there is no ambiguity, but a drastic reduction in the number of available matings. In this case, there is a much less marked departure from randomness, which is nevertheless significant at the 5 per cent level $\left(\chi^{2}=5 \cdot 98, p=\right.$ $0.05)$.

When we examine the adjusted residual for each type of mating there is a pattern of nonrandomness that leaps to the eye-namely a highly significant shortage of like $\times$ like matings. In other words, the flies appear to be mating disassortatively with respect to their inversion karyotype.

\section{Is there non-random mating with respect to size?}

In four of the samples each mother and every male available to be a father was measured prior to having its $A d h$ genotype determined. Although we can infer the genotype of the male who fathered the progeny, the actual individual cannot be 
Table 1 Randomness of matings with respect to the $\alpha / \beta$ inversion

\begin{tabular}{|c|c|c|c|c|c|}
\hline & & & Mostly $\alpha \alpha$ & $\begin{array}{l}\text { Fathers } \\
\alpha \beta\end{array}$ & Mostly $\beta \beta$ \\
\hline \multirow{3}{*}{ Mothers } & $\begin{array}{l}\text { Mostly } \\
\alpha \alpha\end{array}$ & $\begin{array}{l}\text { Observed numbers } \\
\text { Adjusted residuals } \\
\text { Significance }\end{array}$ & $\begin{array}{l}4 \\
8 \cdot 77 \\
\downarrow \downarrow \downarrow\end{array}$ & $\begin{array}{l}36 \\
0 \cdot 09 \\
\text { NS }\end{array}$ & $\begin{array}{l}68 \\
0.94 \\
\text { NS }\end{array}$ \\
\hline & $\alpha \beta$ & $\begin{array}{l}\text { Observed numbers } \\
\text { Adjusted residuals } \\
\text { Significance }\end{array}$ & $\begin{array}{l}16 \\
2 \cdot 93 \\
\uparrow \uparrow\end{array}$ & $\begin{array}{l}54 \\
6 \cdot 18 \\
\downarrow \downarrow \downarrow\end{array}$ & $\begin{array}{l}157 \\
\uparrow \uparrow^{3 \cdot 13}\end{array}$ \\
\hline & $\begin{array}{l}\text { Mostly } \\
\beta \beta\end{array}$ & $\begin{array}{l}\text { Observed numbers } \\
\text { Adjusted residuals } \\
\text { Significance }\end{array}$ & $\begin{array}{l}8 \\
2 \cdot 41\end{array}$ & $\begin{array}{l}61 \\
12 \cdot 21 \\
\uparrow \uparrow \uparrow\end{array}$ & $\begin{array}{c}47 \\
7 \cdot 01 \\
\downarrow \downarrow \downarrow\end{array}$ \\
\hline
\end{tabular}

"Mostly $\alpha \alpha$ " refers to the combined numbers of animals with $A d h-B B$ and $B C$ genotypes. $\alpha \beta$ refers to the number of animals with $A d h-B D$ genotype. "Mostly $\beta \beta$ " refers to the combined numbers of animals with $A d h-C D$ and $D D$ genotypes.

The overall $\chi^{2}=31 \cdot 1, p \ll 0 \cdot 001$.

Adjusted residuals (Haberman, 1973) are distributed as the normal deviate, and indicate whether each type of mating departs significantly from expectations based on random mating. The levels of significance are as follows: NS, $p>0.05 ; \uparrow, p<0.05 ; \uparrow \uparrow, p<0.01 ; \uparrow \uparrow \uparrow, p<0.001$. Upward pointing arrows indicate the observed number was in excess of expectation, and downward pointing arrows, that it was less than expectation.

identified. However, we can calculate the mean size of the males with each genotype. We can then ask if there is any association between the mothers' sizes and the mean sizes of the male genotypes with which they mated.

There are two complications. The animals were collected from natural populations, whose densities were uncontrolled. In consequence, the sizes of individuals differed between samples. In addition there is an association between female size and Adh genotype (Butlin et al., 1982a).

To render the correlation independent of population and genotypic effects, we have expressed the measurements of size as standardised deviates. For each sample we have calculated the mean and variance of each genotypic group of mothers. The size of every mother within that genotypic group was then expressed as a standardised deviate. Next, the mean size of each male genotype was also expressed as a standardised deviate for each sample. We then tested for an association between the mothers' sizes, and the mean size of males of the genotype with which they mated.

The result is that there is a highly significant positive correlation $(b=0.097 \pm 0.035, p=$ 0.0063 ). Larger females, regardless of their genotype, are mated by males of larger mean size than the small females. In other words there is strong positively assortative mating with respect to size. (In passing, this result is perfectly consistent with the finding that it those male genotypes of small mean size that exhibit the greatest mating success (Day et al., 1987). For example, large males may rarely mate, but those that do, mate with large females).

\section{DISCUSSION}

We have presented evidence that under natural conditions, wild flies mate in a positively assortative fashion with respect to size, and in a negatively assortative way with respect to the Adh locus and the chromosomal inversion with which it is strongly associated. These results raise two general questions-what are the mechanisms that lead to these patterns of non-random mating, and what are the consequences of it as far as natural populations are concerned?

There are many possible reasons why mating may appear to be non-random. Firstly, straightforward mechanical constraints on the mating process could generate assortative mating with respect to size. In Coelopa it appears that when a male has mounted a female there is some type of interplay between the male's forelegs and the female's head-possibly her antennae. There must also obviously be interaction of the male and female genitalia. This involvement of structures at the anterior as well as posterior ends of the mating pair could set constraints on the relative sizes of the male and female. It seems likely that only a male of approximately complementary dimensions would be able to inseminate successfully any particular female. This complementarity of sizes has been suggested as the mechanism leading to 
assortative mating in sand fiddler crabs (Christy, 1983) and in some species of toads (Licht, 1976).

A second possible cause of non-random mating is a consequence of behaviour that may be totally unconnected with the mating process itself. If there is non-random distribution of animals, either in space or in time, then the animals may not be equally available to mate. In Coelopa large animals eclose later than small ones (Day et al., 1980) and this might well lead to positive assortment for size. In general, it would seem that this type of explanation would more readily account for positive rather than negative assortment (see Birkhead and Clarkson, 1980; Coulson and Thomas, 1983; Thompson and Moule, 1983).

Darwin (1871) was the first to recognise that females often discriminate between the available males. If females (or males) have different preferences then non-random mating is likely to occur, and, depending on the nature of the preferences, there could be positive or negative assortment. Many biologists have readily accepted female choice as an important component of sexual selection, yet in very few cases is there convincing evidence that it exists. The work of Thornhill (1980) on hanging flies, Majerus et al. (1982b) on ladybirds, and of Andersson (1982) on widowbirds provides the most convincing evidence for female choice. However, only in Adalia does it seem to generate non-random mating.

A slight variant on the female choice theme is one in which there is a preference for (or against) animals that shared a common developmental history. If, for example, litter-mates can recognise the smell of the nest in which they were reared, and then show a preference to mate with animals carrying a different odour, this would generate disassortment in mating. This type of recognition has been demonstrated in several species of insects (Greenberg, 1979; Grant et al., 1980), amphibians (Waldman, 1984), rodents (Davis, 1982; Grau, 1982) and birds (Bateson, 1983). However, only in Nasonia is it clear that mating behaviour is affected. The point being made here is that preferences may not only be for genetically determined characters, but also for environmentally acquired ones. Both mechanisms could generate nonrandom mating. In our experiments on seaweed flies, the animals in each sample developed in an apparently homogeneous cage of decomposing seaweed, and it seems unlikely that individual animals could acquire distinguishably different components of their environment. If there is some type of female or male choice, it seems more likely that it is discriminating between genetic rather than environmental differences.

Another mechanism much less accessible to experimental manipulation involves differential sperm survival. If the survival or efficiency of sperm varies in different females, the populations may no longer appear panmictic. Such differences in gametic efficiency underlie the phenomenon of self incompatibility in plants (Lewis, 1979) and may also exist in invertebrates (Hewitt et al., 1986). We are currently testing for differences in sperm survival in Coelopa.

Finally, if there are differences in post-zygotic survival then with the experimental design we have used with Coelopa, there might appear to be nonrandom mating. We know that homokaryotypes do not survive as well as heterokaryotypes (Collins, 1978; Butlin and Day, 1984). Consequently, there could be an over-estimation of the number of like $\times$ unlike matings. While this type of technical artefact might be contributing to the apparent disassortment, it is most unlikely that it can account for every one of the significant adjusted residuals reported here.

Without further experimental analysis it is not yet possible to identify which of these, or other, mechanisms is responsible for generating the nonrandomness of mating seen in seaweed flies. Nevertheless, we do not need a knowledge of the cause, in order to comment on the consequences of the observed deviations from randomness. By using the deviations from expectation seen in the pooled data (Appendix), we can predict the genotype frequencies in the next generation. These can then be compared with the frequencies expected on the basis of random mating. The outcome is that, with respect to the Adh locus, there is an excess of heterozygotes of about 3 per cent. With respect to the chromosomal inversion the excess is of the order of 2.5 per cent. Measurements of heterozygote excess in natural populations in Britain reveal excesses of about 20 per cent (Butlin et al., 1982b) and in Scandinavian populations of about 25 per cent (Day et al., 1983). It therefore seems that non-random mating could contribute, albeit somewhat modestly, towards the distortion from Hardy Weinberg expectations observed in wild populations of seaweed flies. The generation of heterozygote excesses allows us to speculate on the evolutionary raison d'etre of non-random mating. Since heterozygotes are fitter than homozygotes (Collins, 1978; Butlin et al., 1984), disassortative mating behaviour should lead to an increased proportion of fitter progeny. We are currently attempting to estimate the consequences of 
non-random mating, and of differential mating success, fecundity and viability. Together they constitute a cocktail of selective agents acting on this very large fraction of the genome of Coelopa.

Acknowledgements T. H. Day was supported by a research grant from the Natural Environment Research Council, and R. K. Butlin by a research studentship from the Science Research Council. Their help is gratefully appreciated.

\section{REFERENCES}

ANDERSSON, M. 1982. Female choice selects for extreme tail length in a widowbird. Nature, 299, 818-820.

ARAK, A. 1983. Male-male competition and mate choice in anuran amphibians. In Bateson, P. (ed). Mate Choice, Cambridge University Press, Cambridge, pp. 181-210.

AVERHOFF, W. W. AND RICHARDSON, R. H. 1974. Pheromonal control of mating patterns in Drosophila melanogaster. Behav. Genet., 4, 207-225.

AVERHOFF, W. W. AND RICHARDSON, R. H. 1976. Multiple pheromone system controlling mating in Drosophila melanogaster. Proc. Nat. Acad. Sci. USA., 73, 591-593.

BARLOW, G. W. AND ROGERS, w. 1978, Female Midas cichlids' choice of mate in relation to parents' and to own color. Biol. Behav., 3, 137-145.

BATESON, P. 1983. Optimal outbreeding. In Bateson, P. (ed.) Mate Choice, Cambridge University Press, Cambridge, pp. 257-277.

BIRKHEAD, T. R. AND CLARKSON, K. 1980. Mate selection and precopulatory guarding in Gammarus pulex. Z. Tierpsychol., $52,365-380$.

BURLEY, N. 1983. The meaning of assortative mating. Ethol. Sociobiol, 4, 191-203.

BUTLIN, R. K. AND DAY, T. H. 1985. Adult size, longevity and fecundity in the seaweed fly, Coelopa frigida. Heredity, 54, 107-110.

BUTLIN, R. K., READ, I. L. AND DAY, T. H. 1982a. The effects of a chromosomal inversion on adult size and male mating success in the seaweed fly, Coelopa frigida. Heredity, 49, $51 \sim 62$.

BUTLIN, R. K., COLliNS, P. M., SKEVINGTON, S. J. AND DAY, T. H. $1982 b$. Genetic variation at the alcohol dehydrogenase locus in natural populations of Coelopa frigida. Heredity, $48,45-55$.

BUTLIN, R. K., COLLINS, P. M. AND DAY, T. H. 1984. The effect of larval density on an inversion polymorphism in the seaweed fly, Coelopa frigida. Heredity, 52, 415-423.

CHRISTY, J. H. 1983. Female choice in the resource-defence mating system of the sand fiddler crab, Uca pugilator. Behav. Ecol. Sociobiol., 12, 169-180.

COLLINS, P. M. 1978. Studies on genetic polymorphism in Coelopa frigida. PhD Thesis, University of Nottingham,

COOCH, F. G. AND BEARDMORE, J. A. 1959. Assortative mating and reciprocal differences in the blue-snow goose complex. Nature, 183, 1833-1834.

COOKE, F. AND DAVIES, J. C. 1983. Assortative mating, mate choice and reproductive fitness in snow geese. In Bateson, P. (ed.) Mate Choice, Cambridge University Press, Cambridge, pp. 279-295.

COUlson, J. C. AND THOMAS, C. S. 1983. Mate choice in the kittiwake gull. In Bateson, P. (ed.) Mate Choice, Cambridge University Press, Cambridge, pp. 361-376.
DARWIN, C. 1871. The descent of man and selection in relation to sex. Murray, London.

DAVIS, L. S. 1982. Sibling recognition in Richardson's ground squirrels (Spermophilus richardsonii). Behav. Ecol. Sociobiol., 11, 65-70.

DAY, T. H., DOBSON, T., HILlIER, P. C., PARKIN, D. T. AND CLARKE, B. C. 1980. Different rates of development associated with the alcohol dehydrogenase locus in the seaweed fly, Coelopa frigida. Heredity, 44, 321-326.

DAY, T. H., DOBSON, T., HILlIER, P. C., PARKIN, D. T. AND CLARK, B. C. 1982. Associations of enzymic and chromosomal polymorphisms in the seaweed fly, Coelopa frigida. Heredity, 48, 35-44.

DAY, T. H., DAWE, C., DOBSON, T. AND HILLIER, P. C. 1983. A chromosomal inversion polymorphism in Scandinavian populations of the seaweed fly, Coelopa frigida. Hereditas, $99,135-145$.

DAY, T. H., MILES, S., PILKINGTON, M. AND BUTLIN, R. K 1987. Differential mating success in populations of seaweed flies (Coelopa frigida.) Heredity, 58, 203212.

GRANT, B., SNYDER, G. A. AND GLESSNER, S. F. 1974. Frequency dependent mate selection in Mormoniella vitripennis. Evolution, 28, 259-264.

GRANT, B., BURTON, S., CONTOREGGI, C. AND ROTHSTEIN, M. 1980. Outbreeding via frequency-dependent mate selection in the parasitoid wasp, Nasonia (= Mormoniella) vitripennis Walker. Evolution, 34, 983-992.

GRAU, H. J. 1982. Kin recognition in white-footed deermice (Peromyscus leucopus). Anim. Behav., 30, 497-505.

GREENBERG, L. 1979. Genetic component of bee odor in kin recognition. Science, 206, 1095-1097.

HABERMAN, S. J. 1973. The analysis of residuals in crossclassified tables. Biometrics, 29, 205-220.

HALLIBURTON, R. AND GALL, G. A. E. 1981. Disruptive selection and assortative mating in Tribolium castaneum. Evolution, 35, 829-843.

HEWITT, G. M., NICHOLS, R. A. AND BARTON, N. H. 1986. Homogamy in alpine grasshoppers found in a hybrid zone: possible assortative fertilization.Evolution, In Press.

JOHNSON, L. K. 1982. Sexual selection in a brentid weevil. Evolution, 36, 251-262.

KISER, C. V. 1968. Assortative mating by educational attainment in relation to fertility. Eugen. Quart., 15, 98-112.

LENINGTON, S. 1983. Social preferences for partners carrying "good genes" in wild house mice. Anim. Behav., 31, 325333.

LEWIS, D. 1979. Sexual incompatibility in plants. Edward Arnold, London.

LICHT, L. E. 1976. Sexual selection in toads (Bufo americanus). Can. J. Zool., 54, 1277-1284.

LOWTHER, J. K. 1961. Polymorphism in the white-throated sparrow, Zonotrichia albicollis. Can. J. Zool,, 39, 281292.

MAJERUS, M. E. N., O'DONALD, P. AND WEIR, J. $1982 a$. Evidence for preferential mating in Adalia bipunctata. Heredity, 49, 37-49.

MAJERUS, M. E. N., O'DONALD, P. AND WEIR, J. 1982b. Female mating preference is genetic. Nature, 300, 521-523.

MCLAIN, D. K. 1982. Density dependent sexual selection and positive phenotypic assortative mating in natural populations of the soldier beetle, Chauliognathus pennsylvanicus. Evolution, 36, 1227-1235.

MURTON, R. K. AND WESTWOOD, N. J. 1977. Avian breeding cycles. Clarendon Press, Oxford.

MURTON, R. K., WESTWOOD, N. J. AND THEARLE, R. J. P. 1973. Polymorphism and the evolution of a continuous breeding season in the pigeon, Columba livia. J. Repr. Fert. Suppl., 19, 563-577. 
NELdER, J. A. AND WEDderburN, R. W. M. 1972. Generalized linear models. J. Roy. Stat. Soc. A., 135, 370-384.

O'DONALD, P. 1972. Sexual selections by variations in fitness at breeding time. Nature, 237, 349-351.

O'DONALD, P. 1980. Genetic models of sexual selection. Cambridge University Press, Cambridge.

PARTRIDGE, L. 1983. Non-random mating and offspring fitness. In Bateson, P. (ed.) Mate Choice, Cambridge University Press, Cambridge, pp. 227-253.

SASSAMAN, C. 1978. Dynamics of a lactate dehydrogenase polymorphism in the wood louse Porcellio scaber Latr.: evidence for partial assortative mating and heterosis in natural populations. Genetics, 88, 591-609.

SHEPPARD, P. M. 1952. A note on non-random mating in the moth Panaxia dominula (L). Heredity, 6, 239-241.

SPUHLER, J. N. 1968. Assortative mating with respect to physical characteristics. Eugen. Quart., 15, 128-140.

STALKER, H. D. 1976. Chromosome studies in wild populations of $D$. melanogaster. Genetics, 82, 323-347.

THOMPSON, D. J. AND MOULE, S. J. 1983. Substrate selection and assortative mating in Gammarus pulex L. Hydrobiologia, 99, 3-6.

THORNHILL, R. 1980. Mate choice in Hylobittacus apicalis (Insecta: Mecoptera) and its relation to some models of female choice. Evolution, 34, 519-538.

VAN DEN BERG, M. J., THOMAS, G., HENDRIKS, H. AND VAN DELDEN, W. 1984. A reexamination of the negative assortative mating phenomenon and its underlying mechanism in Drosophila melanogaster. Behav. Genet., 14, 45-61.
WALDMAN, B. 1984. Kin recognition and sibling association among wood frog (Rana sylvatica) tadpoles. Behav. Ecol. Sociobiol., 14, 171-180.

WARNER, R. R. AND HARLAN, R. K. 1982. Sperm competition and sperm storage as determinants of sexual dimorphism in the dwarf surfperch, Micrometrus minimus. Evolution, $36,44-55$.

WONG, T. T. Y., COUEY, H. M. AND NISHIMOTO, J. I. 1982. Oriental fruit fly: sexual development and mating response of laboratory-reared and wild flies. Ann. Entomol. Soc. Am., 75, 191-194.

YAMAZAKI, K., BOYSE, E. A., MIKE, V., THALER, H. T., MATHIESON, B. J., ABBOTT, J., BOYSE, J., ZAYAS, Z. A. AND THOMAS, L. 1976. Control of mating preferences in mice by genes in the major histocompatibility complex. $J$. Exp. Med., 144, 1324-1335.

YAMAZAKI, K., YAMAGUCHI, M., ANDREWS, P. W., PEAKE, B. AND BOYSE, E. A. 1978. Mating preferences of F2 segregants of crosses between MHC-congenic mouse strains. Immunogenetics, 6, 253-259.

YANAI, J. AND McCLEARN, G. E. 1972. Assortative mating in mice: I. Female mating preference. Behav. Genet., 2, 178183.

YANAI, J. AND McClEARN, G. E. 1973a. Assortive mating in mice: II. Strain differences in female mating preference, male preference, and the question of possible sexual selection. Behav. Genet., 3, 65-74.

YANAI, J. AND McClEARN, G. E. 1973b. Assortive mating in mice: III. Genetic determination of female mating preference. Behav. Genet., 3, 75-84. 


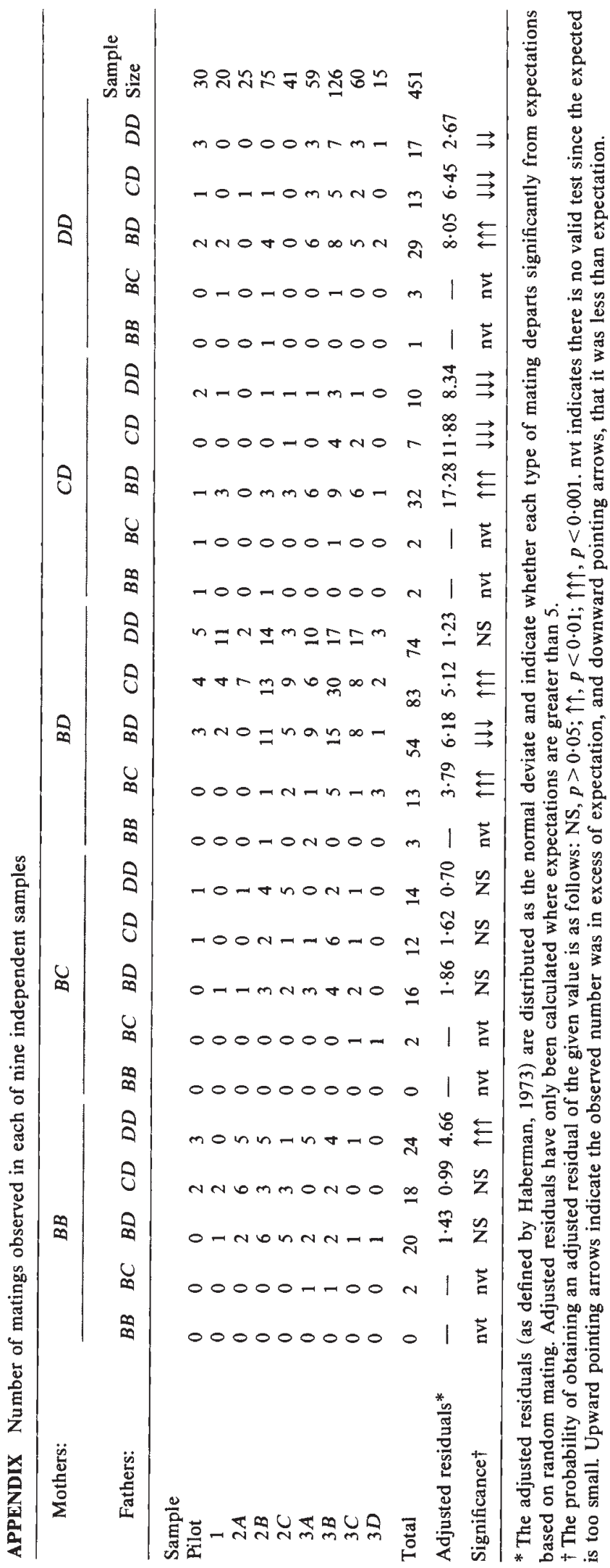

